\title{
The Effects of Repeated Basic Life Support Training on Teachers' Knowledge and Skill Levels: A Quasi-experimental Study
}

\author{
1Department of Nursing, Amasya University Faculty of Health Sciences, Amasya, Turkey \\ 2 Department of Midwifery, Amasya University Faculty of Health Sciences, Amasya, Turkey \\ ${ }^{3}$ Department of Nutrition and Dietetics, Amasya University Faculty of Health Sciences, Amasya, Turkey
}

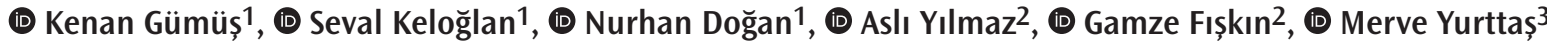

\begin{abstract}
Aim: The purpose of this study is to research the effect of repeated theoretical and practical up to date basic life support (BLS) training that provides teachers the opportunity to improve knowledge and skill levels.

Materials and Methods: This research was a pre-test, post-test, quasi-experimental study. The scope of the study included 65 teachers who participated in theoretical and practical up to date BLS training thirty days apart. A survey form including 19 questions was administered to determine pre-test and post-test theoretical knowledge about BLS. Skill level in BLS was assessed via BLS simulator model in terms of the followings; correct hand positioning, correct head positioning, sufficient depth and frequency of chest compressions.

Results: A significant difference was found between pre-test level of knowledge before BLS training and post-test after the second training session $(p<0.05)$. The levels of competence for correct hand positioning $(38.2 \%$ vs $61.8 \% ; p=0.001)$, correct head positioning $(27.6 \%$ vs $72.4 \%$; $p=0.006)$ and adequate compression frequency (35.0\% vs 65.0\%; $p=0.005)$ increased and excessive compression rate (40.0\% vs $60.0 \% ; p=0.005)$ rose when pre-test and post-test levels were compared.

Conclusion: Promoting teachers' up to date BLS knowledge and skills with continuous training is beneficial. Repeated BLS training showed that the ability of the participants to develop adequate compression frequency with correct hand and head positioning was increased.

Keywords: Basic life support, cardiopulmonary resuscitation training, cardiopulmonary resuscitation simulation
\end{abstract}

\section{Introduction}

Cardiac arrest (CA) known as the cessation of circulation, is an emergency situation with high mortality rate. Basic life support (BLS) is defined as an intervention for obstructed airway due to a foreign body, CA or stroke; initiating basic steps to restore circulation and respiration (1). In the majority of cases, the first person to act in CA is a victim's closest person, usually a nonmedical person. Approximately $70 \%$ to $75 \%$ of cases of CA are witnessed by nonmedical people (2). In the case of CA, BLS performed by a trainedcivil first aider can decrease mortality to a large extent (3). In recent years, trainings and seminars have been organized for individuals who are health providers to increase awareness of BLS. Upon the recommendation of American Heart Association (AHA), BLS training was included in school curriculums to train teachers and students in developed countries (4). In addition, school accidents are a significant cause of death in children over five years old (5), therefore, acquiring BLS skills are important for individuals who are not health care professionals. Teachers in school environment are likely to witness a cardiac case more frequently. Thus, BLS training for teachers can decrease morbidity and mortality rates due to early intervention $(1,3,4,6,7)$. The purpose of this study is to investigate the effect of repeated training on teachers' knowledge and skill level (correct hand and head position giving, provide adequate depth of compression and frequency)

Cite this article as:Gümüș K, Keloğlan S, Doğan N, Yılmaz A, Fışkın G, Yurttaș M. The Effects of Repeated Basic Life Support Training on Teachers' Knowledge and Skill Levels: A Quasi-Experimental Study. Eurasian J Emerg Med. 2020;19(1):46-51.

(C) Copyright 2020 by the Emergency Medicine Physicians' Association of Turkey Eurasian Journal of Emergency Medicine published by Galenos Publishing House. 


\section{Materials and Methods}

\section{Study design}

The study was designed as a pre-test, post-test and quasiexperimental test. The study was conducted with 65 teachers who worked in schools in Amasya city center, voluntarily participated and were chosen by basic random sampling. The consent form was signed by all participants who approved to participate in the study. Data were collected using a survey form to assess level of knowledge of BLS and a BLS simulator model. The study was conducted between May and December 2017. The Scientific Research and Publication Ethics Committee of Amasya University gave consent (no: 15386878-044) and an institutional approval was obtained. The study included the teachers who approved to participate, did not work in a school providing health education and were not professional BLS providers.

\section{Questionnaire form}

A multiple-choice questionnaire based on 2015 AHA guidelines and relevant literature was used to determine teacher's demographical characteristics and knowledge level of BLS procedures (3,812). The questionnaire included 26 questions. Seven questions pertained to teachers' demographical characteristics (age, gender, level of education, years of work experience etc.) and 19 questions assessed BLS practical knowledge (consciousness assessment, chest compression location and frequency, checking airway patency, hand positioning, external defibrillator use etc.). The questionnaire was given to 20 individuals to test the clarity of the form before use in the study. Subsequently, the questionnaire was finalized after making necessary corrections. Each interview took approximately 15 minutes. The same questionnaire form was used for pre-test and post-test.

\section{BLS Simulator Model}

The "CPR Lilly Pro", a half-body BLS simulator model, was used to determine the teachers' level of BLS skills before and after training. The BLS model had the following features; correct hand positioning, correct head and chin positioning, compression depth and frequency. The BLS simulator model testing each skill was successful at least $80 \%$ of the time. Data obtained from the model were transferred to a tablet via bluetooth and recorded.

\section{Training and Practice}

The research was conducted in two phases. Theoretical and practical BLS training was provided after administering the pretest questionnaire in the first phase. The training was set up for 10 hours ( 4 hours theoretical and 6 hours practical). Audio and visual presentations were used in the theoretical training session. Three presentations including fundamental cardiopulmonary anatomy and physiology, the importance of intact cardiopulmonary circulation for survival, state of consciousness, assessment of levels of consciousness and BLS practices structured according to the AHA 2015 guidelines. After theoretical training, a six-hour practice session on the BLS simulator model was conducted until the teacher acquired competency in necessary BLS skills. Following this session, BLS skills were tested on the BLS simulator model with the teachers for 2 minutes and the data were recorded.

To assess the efficacy of repeated training, the same participants were trained with the same training materials on the same BLS simulator model thirty days later. The same questionnaire form was administered as a post-test. After the second phase, BLS training on the BLS simulator model was done for two minutes with the teachers and the data were recorded. Pre-test and post-test answers were recorded. Trainers did not intervene in the meanwhile during the testing on the BLS simulator models. Competencies were all conducted in the same laboratory. Trainers and teachers entered the laboratory solo to prevent interactions with each other.

\section{Statistical Analysis}

Data were analyzed using Statistical Package for the Social Sciences (SPSS) 20 (IBM Corporation, New York). KolmogorovSmirnov and Shapiro-Wilk tests were used for normality. Data were analyzed using numbers, percentage, mean and chisquare (x2). Frequencies and percentages were used to describe categorical parameters. The participants' answers to pre-test and post-test questions were evaluated using the chi-square test. A p-value less than 0.05 is statistically significant.

\section{Results}

Teachers' distribution according to their descriptive characteristics is shown in Table 1. The mean age was $40.30 \pm 8.59$ years and min-max was $26-52$ years. Undergraduate teachers made up $86.9 \%$ of the participants. Of the teachers $99.2 \%$ thought that BLS was required to be known while $87.7 \%$ had not received BLS training before (Table 1).

\section{Findings Before and After Training}

Of the teachers $43.1 \%$ were reluctant to practice BLS before training and $75.4 \%$ knew the practice phases wrong. After the training, the teachers' hesitation rate for practicing BLS decreased to $26.2 \%$ ( $p=0.043$ ) and their rate of correct responses to practice phases increased to $78.5 \%(p<0.001)$. Teachers who knew loss of consciousness symptoms increased from 33.8\% to 56.9\% ( $p<0.007)$ and the rate who knew BLS training phases increased from 9.2\% to $60.0 \%(p<0.001)$. All the teachers had known the correct emergency phone number before training. Of the teachers, 


\begin{tabular}{|c|c|c|c|}
\hline Descriptive Characteristics & Category & $\mathbf{n}$ & $\%$ \\
\hline \multirow[t]{2}{*}{ Gender } & Female & 62 & 47.7 \\
\hline & Male & 68 & 52.3 \\
\hline \multirow[t]{3}{*}{ Age } & $26-34$ & 39 & 30.0 \\
\hline & $35-43$ & 51 & 39.2 \\
\hline & 44 years and older & 40 & 30.8 \\
\hline Mean age (year) & \multicolumn{3}{|l|}{$40.30 \pm 8.59$} \\
\hline \multirow[t]{3}{*}{ Duration of employment } & $1-10$ & 45 & 36.4 \\
\hline & $11-20$ & 40 & 30.8 \\
\hline & 21 years and older & 45 & 34.6 \\
\hline $\begin{array}{l}\text { Mean employment } \\
\text { duration (years) }\end{array}$ & \multicolumn{3}{|l|}{$16.35 \pm 9.77$} \\
\hline \multirow[t]{2}{*}{ Educational level } & Undergraduate & 113 & 86.9 \\
\hline & Postgraduate & 17 & 13.1 \\
\hline \multirow{2}{*}{$\begin{array}{l}\text { Is is necesary for teachers } \\
\text { to know BLS? }\end{array}$} & Yes & 129 & 99.2 \\
\hline & No & 1 & 0.8 \\
\hline \multirow[t]{2}{*}{ Previous first-aid training } & Yes & 16 & 12.3 \\
\hline & No & 114 & 87.7 \\
\hline \multirow{2}{*}{$\begin{array}{l}\text { Teachers included in the } \\
\text { assessment }\end{array}$} & Before training (Pre-test) & 65 & 50.0 \\
\hline & After training (Post-test) & 65 & 50.0 \\
\hline \multicolumn{2}{|l|}{ Total } & 130 & 100 \\
\hline \multicolumn{4}{|l|}{ BLS: Basic life support, n: Number } \\
\hline
\end{tabular}

$76.9 \%$ did not know the necessary assessment duration before starting the BLS training while this rate decreased to $29.2 \%$ after training $(p<0.001)$. The minimal increase in the correct answer to the question "which tissue/organ is not affected negatively in a person whose respiration stops?" was not statistically significant $(p=0.069)$. Of the teachers, $49.2 \%$ gave a correct answer to the length of time that organ damage occured in individuals following CA. This rate increased to $89.2 \%$ after training $(p<0.001)$. Of the teachers, $96.9 \%$ gave an incorrect answer to length of respiration in BLS before training, while $86.2 \%$ gave the correct answer after training $(p<0.001)$. Teachers who responded correctly that chest compressions should not be more than $5-6 \mathrm{~cm}$ for effective BLS was $40.0 \%$, however after the training, every teacher answered this question correctly $(p<0.001)$. Of the teachers, $13 \%$ correctly knew that the number of chest compressions to be performed in one minute during BLS, while this number increased to $95.4 \%$ after training $(p<0.001)$. Of the teachers $61.5 \%$ and $58.5 \%$ did not know the rate of artificial respiration to chest compression in BLS performed on children and adults, respectively, however after training, $92.3 \%$ and $100 \%$ of teachers responded correctly $(p<0.001$ and $p<0.001$, respectively). The rate of those who knew the correct chest compression site was $16.9 \%$, and the number increased to $72.3 \%$ after training $(p<0.001)$. Of the teachers,
81.5\% knew the method used in respiratory assessment before training, however, and all knew the correct method after the training $(p<0.001)$. Of the teachers $69.2 \%$ and $98.5 \%$ answered correctly the necessary procedure to ensure a patent airway before and after training, respectively $(p<0.001)$. Of the teachers, 69.2\% did not know the correct BLS procedure when they faced with a situation in which no response was taken from the patient, patient did not breath and the heart did not beat, however $90.8 \%$ of the teachers learned the correct procedure for this situation $(p<0.001)$. The percentage of participants who knew that only chest compression should be applied to someone who did not have opportunity to make artificial respiration was $46.2 \%$ before training and $100 \%$ after training $(p<0.001)$. Of the teachers 47.2\% knew BLS termination criteria before training and this rate increased to $98.5 \%$ after training $(p<0.001)$. Only $18.5 \%$ of the teachers stated that they knew about external defibrillators and its function, while $95.4 \%$ learnt that this device could be used by civil servant first-aid practitioners, could administer shock when necessary and should be provided in crowded places after training $(p<0.001)$. Table 2 shows detailed information of the responses given by teachers before and after BLS training.

\section{BLS Simulator Model Findings}

According to the findings obtained from the BLS simulator model before and after the training, the level of competence for correct hand positioning (38.2\% vs 61.8\%; $p=0.001$ ), correct head positioning ( $27.6 \%$ vs $72.4 \% ; p=0.006)$, adequate compression frequency ( $35.0 \%$ vs $55.4 \% ; p=0.100$ ) and the rate of excessive compression application ( $40.0 \%$ vs $60.0 \% ; p=0.005$ ) significantly increased when pre-test and post-test results were compared. The increase providing the recommended compression depth (44.6\% vs 55.4\%; $p=0.100$ ) was insignificant (Figure 1).

\section{Discussion}

This study analyzed the change in level of knowledge and skills of teachers who were provided with repeated theoretical and practical BLS training. Schools are places where people live together, and possible life-threatening accidents may occur. Training of teachers with BLS is important in such places. Mortality and morbidity rates can decrease when correct intervention is given by trained specialists appropriately when BLS is necessary. However, uncertainty exists about performing BLS when necessary. A study found some teachers hesitant about practicing BLS when necessary. The fear of hurting the victim due to insufficient skills was found to be a significant reason for hesitating $(13,14)$. Repeated trainings were found to dramatically decrease teachers' uncertainty (43.1 vs 26.2\%), however the uncertainty was not completely removed. A study by Mpotos et al. (15), conducted in a wide sampling, showed 


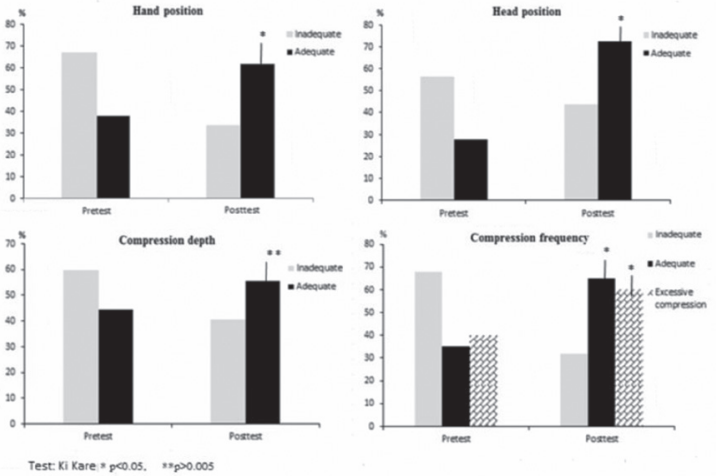

Figure 1. BLS Simulator Model Findings

BLS: Basic life support a positive relationship between teacher's BLS training and BLS applicability. The same study showed that uncertainty in BLS administration decreased in teachers who received training. Therefore, it is thought that current and repeated theoretical and practical training can be effective in terms of decreasing teacher's hesitancy in performing BLS. Another reason for teachers' uncertainty with BLS is the perception that it is only administered by health care professionals. This misperception can be overcome through trainings provided to all civil servants, first-aid providers and teachers.

Previous studies showed that teachers had low to moderate knowledge levels of BLS $(6,16)$. However, other studies found

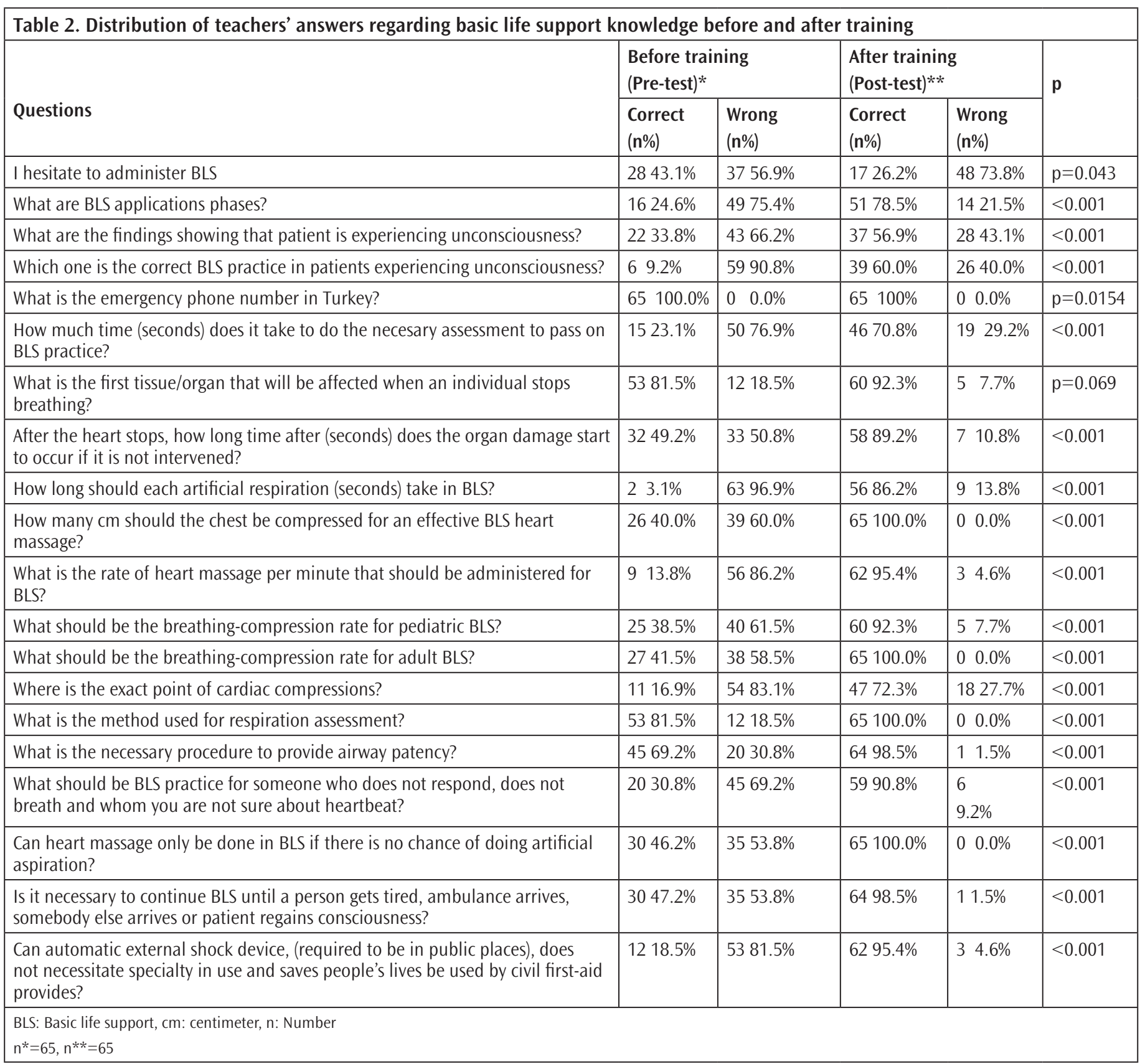


that trainings could boost their BLS knowledge level $(17,18)$. This study found that repeated trainings given under current guidelines significantly increased teachers' practical knowledge. However, the currentness of the provided and repeated training is effective to create this quality and its duration. A study found that teachers' knowledge level increased from $39.79 \%$ to $71.73 \%$ with a BLS training after four hours (19). Although teachers' knowledge level increased with the training, the important consideration was to provide frequent updated knowledge. To this end, repetitiveness of the training plays a key role. Six months following BLS training, teachers experienced loss of knowledge $(20,21)$. Therefore, teachers' level of preparedness can be retained when current BLS training is given regularly and repetitively by public institutions.

It is more objective to assess practical skills in BLS training with BLS simulator model as this assessment protects teachers' level of knowledge and their skills $(22,23)$. This study found that teachers who received training with a BLS simulator model had a significant increase in correct hand positioning, correct head and chin positioning and creating sufficient compression frequencies. The first condition of efficient and sufficient chest compression is to use correct hand position. Even if other skills are appropriate, improper hand position on the chest results in ineffective BLS and survival rate decreases. This study found significant improvement (38.2 vs 61.8\%) in terms of correct hand positioning used by teachers following training. A study by Pichel López et al. (24) found that teachers who received BLS training had improvement in correct hand positioning compared to pre-training, similar to our study. This improvement provided by training teachers was also seen in correct head positioning. Management of airway patency and sufficient respiratory support are considered as important components of BLS application. However, providing airway patency is a controversial issue in previous studies. New recommendations put forward aggressive chest compression. It was reported that stopping compression and slowing it down would lead to fast and continuous deterioration of coronary perfusion pressure (25). This situation was considered by researchers during training. Teachers were notified that if respiration and/or airway support was not provided, BLS practice had to be applied only with chest compression. It was found in the post-test that teachers highly adopted this (46.2 vs 100\%) practice.

At the end of the study, it was found that teachers' skill for providing appropriate compression depth significantly increased. In addition, a significant increase was found in the rate of teachers who applied excessive compressions. Sufficient chest compression is an important component of BLS and there is a direct relationship between chest compression and survival of patients with CA outside the hospital $(26,27)$. Previous studies found that even in short procedures that took 5 minutes, compression depth and frequency criteria determined by AHA were not met (28). Teachers' insufficient experience and physical effort may have affected the result of this study in this way. Ineffective chest compressions cause the practitioner to tire quickly. In addition, trainers determine that chest compressions and frequency must meet the guidelines for an effective BLS practice. Therefore, if teachers focus on the frequency during compressions they can understand if they administer insufficient compression depth and frequency. The focus of appropriate technique in BLS training should be compression rate and depth to improve the quality of BLS. It was determined that creating correct compression depth and rate in BLS were the most difficult skills to acquire $(6,15)$. The least acquired skills in this study were giving appropriate compression depth and preventing excessive compressions.

As a result, BLS training must be given grounded on practical, repetitive and current knowledge. Providing education in this way will enable efficient BLS administration in case of CA at schools and in cultivation of teachers as civil servant first-aid providers.

\section{Study Limitations}

The limitations of the study were as follows: a small sample size, short intervals between the assessments, provision of the questions and trainings by the same people and practical assessments being limited to two minutes.

\section{Conclusion}

BLS is considered a necessary skill to develop. However, the significant point is to train teachers with current and sufficient theoretical and practical training. This study showed that teachers with low levels of BLS knowledge and skills could perform BLS at a higher level and with increased readiness. Consequently, BLS training must be given grounded on practical, repetitive and current knowledge. Providing education in this way will enable efficient BLS administration in case of CA at schools and in cultivation of teachers as civil servant first-aid providers. State institutions and universities should work in cooperation with health care professionals and update their information frequently.

\section{Ethics}

Ethics Committee Approval: The Scientific Research and Publication Ethics Committee of Amasya University gave consent (No. 15386878-044) and an institutional approval was obtained. 
Informed Consent: The consent form was signed by all participants who approved to participate in the study.

Peer-review: Externally peer-reviewed.

\section{Authorship Contributions}

Concept: K.G., Design: K.G., S.K., Data Collection or Processing: K.G., S.K., Analysis or Interpretation: K.G., S.K., N.D., Literature Search: K.G., S.K., N.D., G.F., A.Y., M.Y., Writing: K.G., S.K., N.D., A.Y., G.F.

Conflict of Interest: No conflict of interest was declared by the authors.

Financial Disclosure: This study was supported by Amasya University Scientific Research Projects Commission (Project number: SEB-BAP 17-0146).

\section{References}

1. Dixe M, Gomes JC. [Knowledge of the Portuguese population on basic life support and availability to attend training]. Rev Esc Enferm USP. 2015;49:6409.

2. Qara FJ, Alsulimani LS, Fakeeh MM, Bokhary DH. Knowledge of Nonmedical Individuals about Cardiopulmonary Resuscitation in Case of Cardiac Arrest: A Cross-Sectional Study in the Population of Jeddah, Saudi Arabia. Emergency Medicine International. 2019;2019:3686202.

3. Dwood SB, Al-Mosawi HS, Khudhair AS, Al-Mussawi AA. Evaluate of effectiveness of planned teaching programmer regarding basic life support (BLS) among Nursing Staff in Basra General Hospital. Int J Nurs. 2014;1:15566.

4. Jain M, Sharma L, Meena R, Bansal A, Kakkar S. Cardiopulmonary resuscitation training for medical teachers: Need of the hour. Int J Recent Sci Res. 2016;7:12655-7.

5. Özcebe, H. Status of Child Health in Turkey. In: Ertem M, Inandı T, Çan G, Ergör A, Saşmaz T, Ayoğlu F, Kaya M, editors. Turkey Association of Public Health Professionals Public Health Report. 2012.p.363-73.

6. Al Enizi BA, Saquib N, Zaghloul M.S, Alaboud MS, Shahid M.S, Saquib J. Knowledge and attitudes about basic life support among secondary school teachers in Al-Qassim, Saudi Arabia. Int J Health Sci (Qassim). 2016;10:41522.

7. Yurumez Y, Yavuz Y, Saglam H, Köken R, Tunay K. Evaluation of the level of knowledge of first aid and basic life support of the educators working in preschools. Academic Emergency Medicine Journal. 2007;5:17-20.

8. Neumar RW, Shuster M, Callaway CW, Gent LM, Atkins DL, Bhanji F, et al. Part 1: executive summary: 2015 American Heart Association guidelines update for cardiopulmonary resuscitation and emergency cardiovascular care. Circulation. 2015;32:S315-67.

9. Maconocie IK, Bingham R, Eich C, López-Herce J, Rodríguez-Núñez A, Rajka T, et al. European Resuscitation Council Guidelines for Resuscitation 2015: Section 6. Paediatric life support. Resuscitation. 2015;95:223-48.

10. Dixe M, Gomes JR. [Knowledge of the Portuguese population on basic life support and availability to attend training]. Rev Esc Enferm USP. 2015;49:640-

11. Alotaibi O, Alamri F, Almufleh F, Alsougi W. Basic life support: Knowledge and attitude among dental students and staff in the college of dentistry, King Saud University. Saudi J Dent Res. 2016;7:51-6.
12. Kara F, Yurdakul A, Erdogan B, Polat E. Evaluation of current basic life support information of nurses working in a public hospital. MAKU Institute of Health Sci.J. 2015;3:17-26.

13. Roshana S, Batajoo KH, Piryani RM, Sharma MW. Basic life support: knowledge and attitude of medical/paramedical professionals. World J Emerg Med. 2012;3:141-5.

14. Akpek EA, Kayhan Z. Knowledge of basic life support: a pilot study of the Turkish population by Baskent University in Ankara. Resuscitation. 2003; 58:187-92.

15. Mpotos N, Vekeman E, Monsieurs K, Derese A, Valcke M. Knowledge and willingness to teach cardiopulmonary resuscitation: A survey amongst 4273 teachers. Resuscitation. 2013;84:496-500.

16. Marton J, Veszpremi-Koroknai R, Radnai B, Deutsch K, Peklow E, Banfai B, et al. BLS skills of Hungarian general practitioners. Resuscitation. 2013;84:71-2.

17. Eldesouky El. Effect of a training program for nurses on their knowledge and practice about cardiopulmonary resuscitation. Int J Recent Sci Res. 2016;7:9682-9.

18. Mohamed EA. Effect of Cardiopulmonary Resuscitation (CPR) Training program on knowledge and practices of Internship Technical Institute of nursing students. Journal of Nursing and Health Science. 2017;6:73-81.

19. Lubrano R, Villani A, Cecchetti C, Veronelli P, Turbacci M, Bonci M, et al. Competence assessment of pre-elementary school teachers before and after a pediatric basic life support course for lay rescuers. The American journal of emergency medicine. 2014;32:187-9.

20. Spooner BB, Fallaha JF, Kocierz L, Smith CM, Perkins GD. An evaluation of objective feedback in basic life support (BLS) training. Resuscitation. 2007;73:417-24.

21. Nishiyama C, Iwami T, Murakami Y, Kitamura T, Okamoto Y, Marukawa S. et al. Effectiveness of simplified 15-min refresher BLS training program: A randomized controlled trial. Resuscitation. 2015;90:56-60.

22. González BS, Martínez L, Cerdà M, Piacentini E, Trenado J, Quintana S. Assessing practical skills in cardiopulmonary resuscitation: Discrepancy between standard visual evaluation and a mechanical feedback device. Medicine (Baltimore). 2017:96:e6515.

23. Tobase L, Peres HHC, Tomazini EAS, Teodoro SV, Ramos MR, Polastri TF Basic life support: evaluation of learning using simulation and immediate feedback devices. Rev Lat Am Enfermagem. 2017;25:e2942.

24. Pichel López M, Martínez-Isasi S, Barcala-Furelos R, Fernández-Méndez F, Vázquez Santamariña D, Sánchez-Santos L, et al. [A first step to teaching basic life support in schools: Training the teachers]. An Pediatr (Barc). 2018;89:26571.

25. Durbin CG Jr, Blanch L, Fan E, Hess Dr. Respiratory care year in review 2013 airway management, noninvasive monitoring, and invasive mechanical ventilation. Respiratory care. 2014;59:595-606

26. Stiell IG, Brown SP, Nichol G, Cheskes C, Vaillancourt C, Callaway CW, et al. Resuscitation outcomes consortium investigators. What is the optimal chest compression depth during out-of-hospital cardiac arrest resuscitation of adult patients? Circulation. 2014;130:1962-70.

27. Talikowska M, Tohira H, Finn J. Cardiopulmonary resuscitation quality and patient survival outcome in cardiac arrest: A systematic review and metaanalysis. Resuscitation. 2015;96:66-77.

28. González-Salvado V, Fernández-Méndez F, Barcala-Furelos R, Peña-Gil C, González-Juanatey JR, Rodríguez-Núñez A. Very brief training for laypeople in hands-only cardiopulmonary resuscitation. Effect of real-time feedback. The American journal of emergency medicine. 2016;34:993-8. 